Anja Herb

\title{
Europäisches Gemeinschaftsrecht und nationaler Zivilprozess
}

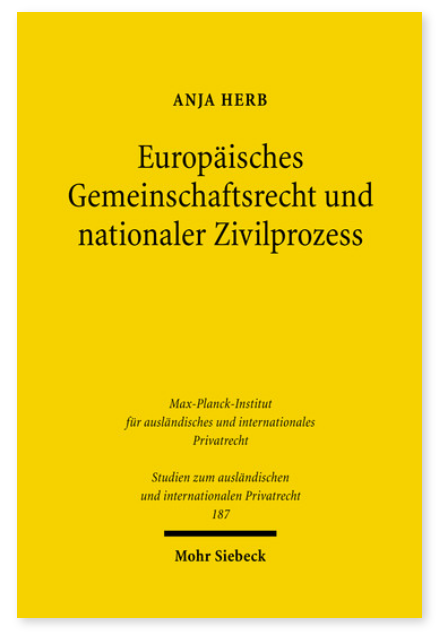

2007. XXI, 324 Seiten. StudIPR 187

SBN 978-3-16-151372-5

DOI 10.1628/978-3-16-151372-5

eBook PDF 79,00€

ISBN 978-3-16-149403-1

fadengeheftete Broschur 79,00€
Wesentliche Voraussetzung für die Wirksamkeit des Europäischen Gemeinschaftsrechts ist seine Durchsetzung durch die nationalen Gerichte. Im Zivilprozess der Mitgliedstaaten besitzen jedoch die Parteien die Herrschaft über die Tatsachengrundlage und den Gegenstand des Verfahrens; sie sind für die Beibringung der entscheidungserheblichen Tatsachen verantwortlich. Die Anwendung des materiellen Rechts ist daher maßgeblich vom Verhalten der Parteien im Zivilprozess abhängig. Anja Herb untersucht das Verhältnis zwischen den nationalen Zivilverfahrensgrundsätzen der Parteiherrschaft und der richterlichen Passivität einerseits und dem Geltungsanspruch des materiellen Gemeinschaftsrechts andererseits. Der Europäische Gerichtshof hat sich wiederholt mit einzelnen Aspekten der Problematik befasst. Nach einer kurzen Darstellung dieser Rechtsprechung untersucht die Autorin rechtsvergleichend die Rollenverteilung zwischen Parteien und Gericht im Zivilprozess in Deutschland, England und Frankreich. Besonderes Augenmerk gilt dabei der Frage, welche Rollenverteilung vorgenommen wird, wenn es im Zivilprozess um die Anwendung des materiellen Gemeinschaftsrechts geht. In einem zweiten Teil widmet sich die Autorin der Frage, ob und inwieweit die nationalen Verfahrensgrundsätze der Parteiherrschaft und der richterlichen Passivität mit dem Gemeinschaftsrecht vereinbar sind. Sie untersucht, welche allgemeinen Anforderungen das Gemeinschaftsrecht an das nationale Verfahrensrecht stellt und welche Vorgaben ihm in Bezug auf die Rollenverteilung zwischen Parteien und Gericht im Zivilverfahren zu entnehmen sind.

Anja Herb Geboren 1977; Studium der Rechtswissenschaften in Trier, London und Bonn; 2006 Promotion; seit 2007 Rechtsanwältin.

Jetzt bestellen:

https://mohrsiebeck.com/buch/europaeisches-gemeinschaftsrecht-und-nationaler-zivilprozess-9783161513725?no_cache=1 order@mohrsiebeck.com

Telefon: +49 (0)7071-923-17

Telefax: +49 (0)7071-51104 